\title{
Effects of Preparatory Classes on the Social Life of Primary School Pupils in Masaka Municipality, Uganda
}

\author{
Maria Theresah Namatovu ${ }^{1}$, Lucy Dora Akello*
}

(C) Uganda Martyrs University

\begin{abstract}
This study examined the effects of preparatory studies on the social life of primary school pupils in Masaka Municipality, Central Uganda. Data were collected from pupils, teachers and school administrators using interviews, focus group discussions and observation. The findings indicated that to a large extent, preparatory classes negatively affected the social life of the pupils. Therefore, it is recommended that schools adhere to the timetable stipulated by the Ministry of Education and Sports.
\end{abstract}

Keywords $\cdot$ Preparatory classes $\cdot$ Child development $\cdot$ Primary education

\section{Introduction}

The purpose of this paper is to share the findings of a study on the effects of preparatory classes on the social life of primary school pupils in order to either stream line or regulate the practice through sensitizing and lobbying the stake holders and the concerned authorities. We shall specifically report on the methodology, findings, discussion, conclusion and recommendations of the study.

A person's social life involves all the activities he or she does when he / she meets with people to share a light moment with them in a relaxed environment. This is in line with Wehmeir (2007) who characterises socializing as meeting and spending time with people in a friendly way in order to enjoy oneself. On the other hand, preparatory classes, whose short form is 'preps' or 'prep classes' are the classes which are conducted outside the normal teaching routine which in Uganda runs from 8:30am to 4:30pm. They are common in boarding schools especially in sub candidate and candidate classes (Namaganda, 2009). This partly agrees with Ezewu (1998) who observed that secondary school boarding students in Nigeria are given a two to three hour session in the evening to revise their books. However, while in Nigeria students are left to read on their own, in Uganda

\footnotetext{
${ }^{1}$ Blessed Sacrament Secondary School Kimaanya, Masaka, Uganda

${ }^{2}$ Faculty of Education, Uganda Martyrs University, *Corresponding author: lakello@umu.ac.ug
} 
teachers engage pupils in real teaching and learning which starts as early as 5:00am, and in the evening it is extended to as late as $10: 30 \mathrm{pm}$.

According to the National Curriculum Development Centre (2000) schools are supposed to conduct classes from $8: 30 \mathrm{am}$ to $4: 30 \mathrm{pm}$ with a thirty minutes break at 10:00am and a one hour lunch break at $1: 00 \mathrm{pm}$. The time after 4:30pm is meant for them to socialize through co-curricular activities and community work. Nduhukire (1998) adds that at 5:00pm they break off break and return home to interact with their families and respective communities. However, many schools have decided to fix classes before 8:30 am, and after 4:30pm ignoring co-curricular activities, yet they extend teaching too late in the night when pupils are supposed to be resting (Namaganda, 2009). This reduces the time the pupils would have spent interacting socially. Unfortunately, this widely spread practice is receiving little attention from stake holders and policy makers, possibly because its effects on the social life of pupils has not been established. Therefore, this study examined the effects of preparatory classes on the social life of the pupils.

Scholarly evidence showing the positive effects of prep classes on the social life of the pupils indicates that the classroom environment which is typical of the prep classes can foster communication, cooperation, competition, conflict, accommodation and assimilation, the social processes that dominate the social life of the children. Confining pupils in a classroom creates a peer environment which enables them to develop common interests and a strong social bond. Dettart, Srouge \& Cooper (1986) go on to argue that schools provide opportunities for cross ethnic contact and friendships that are unavailable in a child's own neighbourhood. The collaborative learning experiences such as assignments and discussions also foster alliances and promote speaking and listening skills. Peer pairing on its own can boost the social interaction of children with interaction difficulties. When they are paired together with the socially active ones, they open up. The subject content delivered by the teacher can also enhance the social interaction of the pupils, for Dettart, Srouge \& Cooper (1986) stated that curricula have been designed to encourage cooperation and pro-social behaviour among the learners. In addition to this, a democratic teacher who is attentive, encouraging, engaging, sensitive and responsive to children's changing needs (Omona, 1998) creates an environment which allows pupils to interact freely. The absence of the teacher from class encourages interaction among the pupils. Dixie (2003) stated that in that brief moment before the teacher arrives the pupils have already established a high social bond which they are reluctant to change. A classroom with posters, pictures and pupils' work displayed on the walls also encourages discussions and arguments which are healthy social processes, and the pupil to pupil, and teacher to pupil conflict resolution programs offer children alternative ways of handling problems which confirms what Omona (1998) stated that conflicts, when resolved, have been known to yield better understanding among members of the social system.

However, the classroom as a venue has never been meant for pupil social interaction. In all schools, socializing is reserved for other places such as the play ground, the court yard, the dormitories and the dining halls. Therefore, confining children limits the number of people they socialize with yet Beaver (1994) says that there is a range of people who are significant in the social development of the child especially family and community members. Prep teaching itself violates holistic education which is the goal of primary education in Uganda. The National Curriculum Development Centre (2000) states that primary education is for the development and maintenance of sound mental and physical health among learners, the installation of the values of care and cooperation, and the 
appreciation of cultural, moral and spiritual values of life. Excessive pumping of pupils with theory has adverse psychological effects on them. Erickson (1993) states that pupils require real task they can accomplish, so if a child finds school a place where his previous accomplishments are disregarded, if at school his individual interests are overlooked, or if too much is expected of him, he may develop a feeling of inadequacy and inferiority which hamper his future social development. Dictated marathon grouping of children in the classroom retards individualism and creativity which confirms what (Erickson, 1993) observed, that all human beings are individual by nature, and they do not tick in a uniform way or for the same reasons. Prep classes insist on the use of English at the expense of pupils' local languages which hinders effective communication among them. This agrees with Moore (1996) who stated that the West Indian child in an American school is told on first entering the school that his language is second rate; namely, the only way he knows to speak is the wrong way to speak. In the classroom, all children are expected to conform to the common expectations of the school, yet in their social life their behaviour is unstructured (Ezewu, 1998). Ansu (1984) noted that interaction among pupils in Tanzanian schools was discouraged, and the exchange of ideas was equated with 'shouting' which was an offence, yet to Beaver (1994) pupils help each other through the quarrels they have and the negotiations and discussions they have.

The activities conducted in the classroom are academic and far from social. They include lessons, assignments and academic discussions. Similarly, the evaluation conducted in the classroom is meant to assess the academic progress of the pupils, but not their social performance. This shows that social activities are not part of the outcome expected of a child in the classroom. The environment inside the classroom discourages social interaction. Ansu (1984) noted that in Tanzanian schools, the classroom environment only generates fear for authority among pupils. The sitting arrangement presupposes that the pupils are empty pots which can never learn from each other but from one authority, the teacher. They are made to sit in such a way that each face speaks to the back of another pupil's head, which rules out any possibilities of interaction among the pupils. The message on the posters and charts can also be disastrous. Moore (1996) noted that in America, a Black child under the influence of White people's pictures in class develops a deep inferiority complex. He soon loses motivation since at best; the learning experience is an elaborate irrelevance to his personal life situation, but above all, a racially humiliating experience. In many primary school classrooms in Uganda, leadership in class is autocratic with too much power invested in the personality of the teacher. This confirms what Ansu (1984) observed in primary schools among the Silasa of Northern Ghana where there was almost a total absence of spontaneity in the classroom.

\section{Methodology}

A case study research design was adapted for the study of the effects of preparatory classes on pupils in primary schools in Masaka Municipality in Masaka district, Uganda. Qualitative research method was employed to facilitate the study of the pupils in their natural classroom setting. Purposive sampling was used to select the municipality and district of the study because Masaka Municipality was the fastest growing region in the district in as far as education was concerned, It has the highest number of primary and secondary schools in the entire southern region of Uganda which includes the districts of Masaka, Kalangala, Rakai, Ssembabule, Kalungu and Lwengo. It is also home to several 
branches of universities which include Uganda Martyrs University-Nkozi, Kampala University, Kampala International University and Muteesa I Royal University. Purposive sampling was used to select only nine schools that conducted prep classes for the study, taking three from each of the three divisions of the municipality. A sample of 180 participants consisted of pupils, teachers and administrators was distributed as follows: 9 administrators, 36 teachers and 135 pupils. Such a sample size was chosen to ensure delivery in order to make the research findings applicable to the whole population: representativeness so as to fulfil the questions the study addressed.

Once again, judgmental sampling was used to select school administrators and teachers since it was suitable in cases where a researcher was interested in views held by particular categories of people (Cohen, 2007). However, the pupils were selected using simple random sampling since preparatory classes were compulsory to all pupils of the classes which were subjected to this program. School administrators were chosen because they were responsible for designing and scheduling the preparatory classes. They also monitored and supervised the implementation of preparatory teaching program. Teachers were chosen because they were actively involved in conducting the preparatory classes, while the pupils were the respondents who attended these classes. Pupils' experiences were vital for this study since they were aware of how the preparatory classes affected their social life.

For the purpose of creating an informed position as a basis for effective interaction with respondents, secondary sources of data such as books, electronic publications, periodicals and journals were examined. These provided useful information on the nature of the social life of primary school pupils, the nature of the preparatory classes conducted in primary schools, and the effects of the classroom on the social life of the pupils, which created a good basis for the researcher to study the effects of preparatory classes on the social life of the primary school pupils. Primary data on the other hand was collected using interviews, focus group discussions and observation. These were employed during interface with the school administrators and the parents since they were known to help bring out the views and attitudes of respondents (Fraenkel \& Wallen, 2006). Their flexible nature suited the busy schedules of the administrators and the parents. With teachers and pupils, the focus group discussion technique was used to get in-depth information from them since it was known to provide opportunity for interaction and fruitful discussion (Bell, 2005). This helped to build confidence particularly among the pupils, which enabled them to express their ideas freely. Focus group discussions also saved teachers' time, but above all they minimized misunderstanding of questions since the researcher had the chance to explain what particular questions required. Observation was also employed on the pupils in a prep class setting because this study sought to investigate the actual social behaviour of the pupils who were exposed to the preparatory classes. This helped to bring out the real context of the exercise of conducting classes during preparatory study time. Observation helped to fill the gaps left behind by interviews and focus group discussions.

The researcher mainly used qualitative data analysis methods since the study focused on the respondents' perceptions and practices which required interpretation (Cohen, 2007). Data was classified under the major themes of the study using a coding system using the Microsoft Word package. Quantitative methods were also employed to illustrate the degree of these perceptions and practices among the respondents. Responses in their respective themes were presented according to the frequency of their occurrence among 
the different stake holder groups using pie charts, tabular and graphical illustrations of the Microsoft Excel program.

\section{Findings and Discussion}

The first objective of this study was to examine the nature of the social life of primary school pupils. Data analysis and interpretation revealed that: pupils in Masaka Municipality understood the concept of social life to mean the way people relate to each other in the community by meeting and spending time together purposely to enjoy themselves. This agreed with Wehmeir's (2007) definition of social life, which is, meeting and spending time with people in a friendly way in order to enjoy oneself. Sports and games were the most popular pupil social activities. They included a wide range of formal games such as football, netball and volleyball, and informal games which the pupils referred to as "just playing". These included all the locally invented children's games such as "okwepena" (dodge-ball), 'round-game', "put', "salamia", "beebe" and "dduulu". All these games involved active contests between individuals or groups of people. Other social activities included the verbal ones such as cracking jokes and conversations; sharing edibles, and doing house hold chores together. Watching television and listening to radio, prayers, reading story books and news papers, as well as touring were also common. This finding meant that pupils had a rich social life that could facilitate their all round growth and development.

At school, the pupils engaged in social activities at break time between 10:00am and 11:00am, at lunch time from $1: 00 \mathrm{pm}$ to $2: 00 \mathrm{pm}$, and after classes, between $4: 30 \mathrm{pm}$ and 7:00pm, which implied that most of their time at school was spent in class doing academic work at the expense of social activities, which negatively impacted on their social life. The places where pupils carried out their social activities included play grounds, compound, dormitories, classrooms, neighbours' homes and at water sources such as wells and bore holes, the dining hall, canteens, inside the house at home, and in the gardens. Churches and mosques, libraries and off-school locations such as the nearby trading centres, the Uganda Wild life Education Centre, the Entebbe International Airport, in Didi's World and in Kampala and Jinja industrial areas were also popular places for pupils' social activities. This finding implied that the pupils could utilize any opportunity to socialize in any place and in any way they deemed interesting. This social interaction resulted in the creation of friends whom Kail (1998) believes with time develop similar interests, attitudes and values. This explains the rich nature of their social life which, if not suffocated by excessive academic work can facilitate their all round growth and development.

The second objective of this study was to identify the nature of the preparatory classes conducted in primary schools. The findings indicated that: prep classes were conducted outside the normal teaching hours authorized by the Ministry of Education and Sports. They were conducted between 5:00am and 8:30am, and in the evening between 5:00pm and 10:30pm. This implied that they encroach on the time the pupils would have spent socializing, which confirms what Namaganda (2009) observed, that pupils are taught in the morning prep at 5:00am, they do not rest throughout the day yet they were also taught in the evening prep from 7:00pm to 10:00pm.

Prep classes were conducted in the upper primary section of P5, P.6 and P.7 especially in boarding schools purposely to prepare pupils for Primary Leaving Examinations, and 
for that matter, they were compulsory. This implies that all the pupils in the upper primary section missed out on the social activities, which showed that schools had no regard for the importance of social interaction in the growth and development of the pupils. This confirms what Bishop (1985) noted that such schools bear no relationship to their surroundings - they only produce people who are foreigners in their own society.

Prep classes were carried out in the pupils' respective classes whose setting was the traditional one with seats arranged in rows and columns with the teacher at the front as a fountain of both information and knowledge. This setting featured no possibility for group work and pupil interaction (Young, 2000) which denied the pupils the chance to open up and interact freely with each other. All the activities carried out in the prep classes were academic. They included lessons, assignments, discussions, tests and examinations, which confirmed what Namaganda (2009) observed that administrators believe that if they do not teach during prep time, the pupils would fail. However, this contrast with Erickson (1993) who believes that to help children develop a sense of accomplishment does not mean merely giving all of them good marks and passing them on to the next grade.

The third objective of this study was to examine the effects of prep classes on the social life of the primary school pupils. Findings revealed that these classes impacted more negatively on the social life of the pupils. The negative effects were classified into the timing-related effects and the activity-related effects. The timing related effects carried more weight $(62 \%)$ than the activity-related effects $(38 \%)$.

The timing related effects resulted from the time the prep classes were conducted, that is, from 5:00am to $8: 30 \mathrm{am}$ and from $5: 00 \mathrm{pm}$ to $10: 30 \mathrm{pm}$. Confining pupils in their classes denied them time to play, which is their most favourite form of social interaction. This confinement contradicts with what Kail (1998) a sociologist stated, that children find themselves interacting more with their peers in largely unstructured situations with minimum adult supervision. Prep classes also denied pupils the time to do their private work such as bathing and cleaning their dormitories. This also violates what Nduhukire (1998) an education expert recommended, that at 5:00pm, pupils should break off and return home to interact with their families and communities by helping with house work, yet doing house work was another means through which pupils socialized. Prep classes denied pupils parental love contradicting with what Beaver (1994) stated that there is a wide range of people who are significant to the development of the child, especially family and community members. They also denied the pupils the opportunity to discuss personal issues since the teachers imposed content dictated by the curriculum on the class by maintaining a limited discussion-like format. There was also professional misconduct on the side of the teachers who exploited the dark to defile the pupils. This crime partly explains the rampant pregnancies among pupils, but it also sets a bad example for the children who are bound to misbehave should they get the opportunity to socialize.

The activity-related effects originated directly from the activities carried out during the prep classes. These classes were hectic. They denied the pupils the opportunity to rest and refresh their minds. This agrees with what Namaganda (2009) observed that pupils do not have the luxury to sleep on what they were taught the previous day. The beating which was common in these classes destroyed all the possibilities of enjoyment. In relation to this, Ansu (1984) warned that such character could breed in the pupils a feeling of helplessness and pessimism which (Young, 2000) said also condemns pupils to an early exit from the education system. Prep classes hindered effective communication because the debates and discussions were held in English at the expense of the local languages 
which the pupils use in their social interaction. This agrees with what Moore (1996) noted, that West Indian children in American Schools are told on first entering school that the only way they knew to speak was the wrong way to speak. However, he went on to remark that children who experience a language rich environment with opportunities for play establish early thought and speech patterns which are essential for their social development.

Prep classes were associated with health-related problems, the most common being fatigue which results from denying pupils adequate time to rest. Consequently, they missed out on the normal classes due to dozing during the time they are supposed to be studying normally. The strict rules governing the exams, tests and assignments destroyed team work, for any exchange of ideas was an offence and therefore highly punishable. This confirms what Ansu (1884) observed in Ghanaian schools where there was almost total absence of spontaneity in the classroom, and in Tanzanian schools where any discussions among pupils in the classroom was equated to shouting which was an offence. The academic activities conducted in these classes were monotonous and boring which is dangerous because Erickson (1993) warned that if a child found school a place where his previous accomplishments were disregarded, and if at school his individual needs were overlooked, or if too much was expected of him, and if he was made to feel that achievement was beyond his ability, he would develop a feeling of inadequacy and inferiority which are destructive to his social life.

The positive effects of prep classes on the social life of the pupils were less significant, for example, the confinement of pupils in the classroom encouraged the creation of friendships though the absence of groups and active interaction limited this so friendships never exceeded a pupil's most immediate neighbour. This largely disagrees with Gurian \& Pope (2011) who claimed that children in the same class find it easy to share experiences when they are grouped together for a long time. Reading story books and newspapers enhanced speaking and listening skills which triggered conversation and argument which are important social processes in pupils. Conflict resolution skills were boosted in cases where the pupils reported misunderstandings to the teacher, however, the misunderstandings themselves were academically related hence they never originated from the pupils' social realm.

However, other positive effects such as democratic leadership which is supposed to encourage pupils to open up; the absence of the teacher in class which gives pupils the opportunity to interact; and non-academic activities which encourage group formation and social interaction were not among the responses. This explains the insignificant positive effects which prep classes have on the social life of the pupils.

\section{Conclusions and Recommendations}

In view of these findings, this study concluded that pupils understood social life to mean the way people relate to each other in the community by meeting and spending time together to enjoy themselves. Pupils engaged in a wide range of social activities dominated by play and conversation which facilitated their all round growth and development. They carried out these activities predominantly in the play ground, in the compound, and in their dormitories. This implied that pupils could utilize any place to socialize, given the opportunity. At school, they socialized at break time (between 10:00am and 11:00am) and at lunch time (from 1:00pm to 2:00pm) which implied that most of their time was spent on 
academic work at the expense of social interaction. This negatively impacted on their social life.

Prep teaching was the act of conducting classes outside the normal teaching hours stipulated by the Ministry of Education and Sports, which is before 8:30am and after 4:30pm to as late as $10: 30 \mathrm{pm}$. Prep teaching, which was widely practiced in primary schools in Masaka municipality, had been going on for years which meant that it had denied pupils the time for social interact for long. Schools adopted prep teaching mainly to prepare their pupils for P.L.E through rigorous tests and assignments, none of which was intended to promote the social life of the pupils. These classes were conducted in P.5, P.6 and P.7, the classes of Upper Primary Section. School administrators and teachers argued that these classes needed to complete the syllabi and to start rigorous revision as early as possible. Prep classes were compulsory for all the pupils in the respective classes where they were scheduled. This meant that all these pupils missed out on the social activities in the school, which negatively impacted on their social life. Prep teaching was conducted from the respective classrooms-typically traditional in setting which meant that all pupils sat in columns and the teacher occupied the flow as a fountain of knowledge. Such a setting could not foster social interaction among the pupils. The activities carried out in the prep classes were all academic. They included teaching, revision exercises, written assignment also known as home work, tests and examinations, teacher - led academic discussions. This meant that these classes deliberately ignored pupils' social activities, which negatively impacted on the pupils' social life.

There were more negative effects of prep classes on the social life of the pupils than the positive ones. The timing related effects were those effects which resulted from the time the prep classes were conducted. They included denying pupils time for private work, denying them time to play, and opportunities to discuss personal issues, parental love, and professional misconduct on the side of the teachers. The activity-related effects were those which originated directly from the activities that were conducted during the prep classes. They included health-related problems, the hectic nature of the prep classes, and the destruction of cooperation and teamwork among the pupils. The monotonous and boring nature of the prep classes, the destruction of communication and the beating which destroyed the possibility of the pupils to enjoy the prep classes. However, the positive effects included pupils getting to know each other as a result of confinement in a classroom setting; pupils spending more time with the adult supervision of their teachers, pupils learning to open up their feelings through the discussions held during the prep classes, the inculcation of communication and expression skills in pupils through reading story books; and the development of respect for one another. Generally, this study clearly revealed that preparatory classes had adverse effects on the social life of primary school pupils since they curtailed the major forms of social interaction which dominated the social life of the pupils. These were communication, cooperation, competition, conflict, accommodation and assimilation (Omona 1998, Ezewu, 1998, La Verne \& Anderson, 1977).

It is against this background that the following recommendations were made. For schools to promote the social life of the pupils they need to broaden the variety of social activities which will enable pupils to have a wide range of social activities to choose from. They need to provide social infrastructures such as play grounds, and logistics especially play items like balls, ropes and toys. Teachers need to encourage pupils to freely engage in indigenous social activities which they engage in at home. These social activities are cheap 
and sustainable but they also make school friendly. Schools need to allow pupils to use their local languages in their social interaction because this helps to bring out maximum enjoyment of the social activities. Schools also need to respect the teaching time table stipulated by the Ministry of Education and Sports.

To curb the practice of prep teaching, the National Curriculum Development Centre has to review the primary school curriculum in order to include more examinable practical aspects than the theoretical aspects. This will help reduce the rigorous pumping of theory among pupils as they will have practical aspects to engage in which will reduce prep teaching. There was also need to broaden the inspection of schools to include all that takes place after the normal teaching hours. Parents need to actively participate in decision making at school. This will minimize their tendency to simply accept policies dictated by schools. To regulate this excessive teaching, school inspectors should introduce abrupt inspection, and bringing to book the schools which violate the legitimate time table.

To mitigate the negative impact of prep classes on the pupils, schools need to introduce guidance and counselling. Teachers have to stop the harsh treatment of pupils by abiding to the policies of the Ministry of Education and Sports, and the teachers involved in professional misconduct have to be brought to book. This will help to make schools more pupil-friendly which would promote social interaction among the pupils there by boosting their social life.

\section{References}

Ansu, D. (1984). Education and Society: a Sociology of African Education. London: Macmillan Education Ltd.

Beaver, M., 1994. Babies and Young Children. London: Thornes Publishers Ltd.

Bell, R. R., (Ed.) (1968). Sociology of Education- A Source Book. Illinois: Dorsey Press.

Bishop, G. (1985). Curriculum Development: A Text Book for Students. London: Macmillan Education Ltd.

Cohen, L., et al. (2007). Research Methods in Education (6 $6^{\text {th }}$ Edition). Oxon: Routledge.

Dettart, G. B., Srouge L. A. \& Cooper R.G., 2000. Child Development-Its Nature and Course $\left(4^{\text {th }}\right.$ Edition). Burr Ridge: McGraw Hill Company.

Dixie, G. (2003). Managing your Classroom London: Continuum.

Erikson, E. (1993). Developmental Stages: A Healthy Personality for Every Child. In

Glen, H. \& Forrest, W.P. Curriculum Planning- A New Approach. (6 ${ }^{\text {th }}$ Edition). Boston: Ally \& Bacon.

Ezewu, E. (1998). Sociology of Education. Lagos: Longman.

Fraenkel, J.R. \& Wallen, N.E., 2006. How to Design and Evaluate Research in Education. ( $6^{\text {th }}$ Edition), New York: McGraw-Hill.

Gurian, A. \& Pope A. Do Kids Need Friends.

http://www.aboutourkids.org/articles/do_kids_need_friends). Viewed 11 March 2011

Kail, R.V. (1998). Children and their Development. (4 ${ }^{\text {th }}$ Edition) New Jersey: Pearson \& Prentice Hall.

La Verne, T. \& Anderson R. (1977). Sociology: The Study of Human Relationships. (2 ${ }^{\text {nd }}$ Edition) New York: Harcourt Brace Jovanovich.

Moore, S. (1996). Sociology Alive. ( $2^{\text {nd }}$ Edition), London: Thornes Publishers Ltd.

Namaganda, A. (2009). How Study Work Load is Suffocating Creativity. The Daily Monitor, $20^{\text {th }}$ July, pp. $17-18$. 
Namaganda, A. (2010).P.L.E. Results Out. The Daily Monitor, 20 July, pp.1-3.

National Curriculum Development Centre. (2000). Primary School Curriculum. (Vol. II). Kampala: National Curriculum Development Centre.

Nduhukire, E. (1997). Development of Uganda's Education System and Professional Teaching Skills. (National Primary Teachers' Educational Series: Professional Education Studies Book 2.) Kampala: National Curriculum Development Centre.

Omona, A. M. (1998). Sociology of Education: Foundations of Education. Kampala: Makerere University Printery.

Wehmeir, S. (Ed.) (2007). Oxford Advanced Learners Dictionary. (7th Edition) London: Oxford University Press.

Young, M. E. (Ed.) (2000). From Early Child Development to Human Development Investing in Our Children's Future. Washington D.C.: World Bank.

\section{Author Biography}

Namatovu Maria Theresah is a teacher, and the head of the Christian Religious Education Department, at Blessed Sacrament Secondary School Kimaanya in Masaka district, Uganda.

Akello Lucy Dora is the coordinator of the Quality Assurance Committee at Uganda Martyrs University. She is also a lecturer at the Faculty of Education at the University. Her research interests focus on Bilingual Education, Language Pedagogy, and Quality Assurance. 